\title{
ALLOWABLE RESIDUAL DISPLACEMENT OF GRAVITY QUAYWALLS GIVEN BY OPTIMUM SEISMIC COEFFICIENT FROM ECONOMICAL VIEWPOINT
}

\author{
By Tatsuo UWABE*
}

\begin{abstract}
Caces of earthquake damage to gravity quaywalls were collected for past earthquakes, and the quantity of earthquake damage which means the residual displacement after earthquakes and the cost of damage was then analyzed. An estimation method to give this quantity of the damage (residual displacement and cost) was presented, using the empirical equation which is the function of the ratio of the corresponding seismic coefficient of the ground acceleration to the seismic coefficient which gives the safety factor of unity in the stability analysis of the design standard. An optimum seismic coefficient from an economical viewpoint and an allowable residual displacement which was defined as an expected seismic damage displacement given by such optimum seismic coefficient were then studied for the rational seismic design, on the basis of the quantitative estimation method of the cost of damage.

Keywords: earthquake resistant design, seismic damage, residual displacement, seismic coefficient, gravity quaywall
\end{abstract}

\section{INTRODUCTION}

Currently in Japan, there is a high possibility of the occurrence of a large earthquake in Tokai Area, a central part of Japan, in the near future, and thus many kinds of investigations for earthquake preparedness have been done. One of the investigations related to ports that may become key locations for the transportation of emergency goods immediately after an earthquake, is a survey on the earthquake resistance capability of port facilities to estimate the number of port facilities available after the earthquake. In this survey, the seismic stability of port facilities has been judged by the evaluation method reported by Tsuchida et al. ${ }^{1)}$. According to this method there are only the two kinds of analyzed results of no damage, and collapse. However the actual seismic damage of port facilities shows a gradual change to collapse.

It is now necessary to assess the potential seismic damage quantitatively by the following reasons.

i) If the extent of damage to port facilities is small, they can still serve for the temporary transportation of urgent goods. It is therefore important to know whether the port facilities are available after earthquakes, by prior estimation of the extent of damage.

ii) Because the number of port facilities which are assessed to be damaged is large and because they cannot be reinforced at the same time, it is necessary to decide the priority of reinforcement and an effective reinforcing method according to the extent of potential damage.

With the background described above, the present study is concerned with the development of a quantitative estimation method of seismic damage to port facilities. It is further aimed at establishing the rational earthquake resistant design by utilizing the quantitative estimation method of seismic damage thus

* Member of JSCE, Dr. Eng., Chief of Earthquake Disaster Prevention Laboratory, Structural Engineering Division, Port and Harbour Research Institute, Ministry of Transport (Nagase 3-1-1, Yokosuka, Japan) 
developed. In this earthquake resistant design, it is necessary to give an allowable value of seismic damage deformation. The seismic damage deformation means the swelling and settlement of face line of the wharf, the tilting of wall and so on. The allowable value is considered to be given from the viewpoint of the berthing function, the structural stability, the economy and so on. In the present study, the allowable residual displacement from the economical viewpoint is investigated. An optimum seismic coefficient from the economical viewpoint and an allowable seismic damage given by such seismic coefficient is sought for, using the quantitatively estimated potential seismic damage. The structures analyzed in this study are a gravity type quaywall, which is a typical berthing facility in Japan, and a gravity revetment.

In this report, historical cases of seismic damage to gravity quaywalls are first described. On the basis of these cases, a quantitative estimation method of seismic damage to gravity quaywalls is then presented. Lastly, an optimum seismic coefficient and an allowable residual displacement are derived by applying the quantitative estimation method to several cases of gravity structures with the cost analyses.

\section{CASES OF SEISMIC DAMAGE TO GRAVITY QUAYWALLS}

\section{(1) Earthquake, ports and gravity quaywalls discussed in this report}

A gravity quaywall is a typical berthing facility to moor ships in Japan. The structural types of gravity quaywalls are classified into the caisson type, the concrete block type, the L-shaped concrete block type, the cellular block type and the wave absorbing vertical wall type. Fig. 1 illustrates the caisson type of gravity quaywalls. Table 1 shows the number of port facilities damaged by past erthquakes from 1923 to 1978. The details of these 679 data were shown in the report of Uwabe ${ }^{2}$. In the study on the quantitative estimation of seismic damage to gravity quaywalls the episodes of gravity quaywalls clearly damaged by liquefaction were excluded from this report.

\section{(2) Quantification of damage to gravity quaywalls}

a) Seismic damage deformation

In a survey of seismic damage the swelling and settlement of face line of the wharf, the tilting of wall, the settlement of apron and other factors as shown in Fig. 2 was measured, and the length of damage section in one berth (damage length) was also measured. In this report, these measured values and the damage deformation ratio (the ratio of the maximum swelling to the wall height which is the height between sea bed

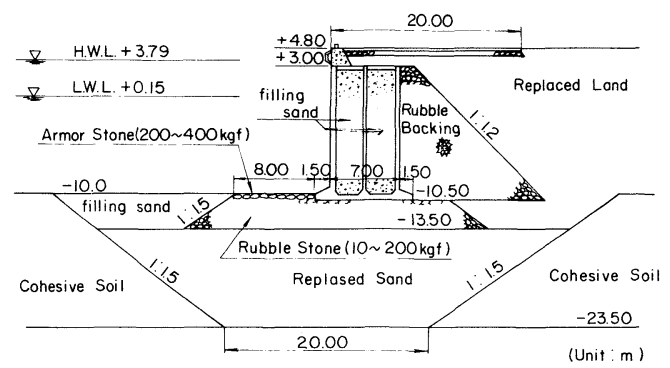

Table 1 Data of Seismic Damage to Port Facilities.

\begin{tabular}{|c|c|l|l|}
\hline $\begin{array}{c}\text { Number of } \\
\text { earthquakes }\end{array}$ & $\begin{array}{c}\text { Number of } \\
\text { ports }\end{array}$ & \multicolumn{1}{|c|}{$\begin{array}{c}\text { Structural } \\
\text { type }\end{array}$} & $\begin{array}{c}\text { Number of } \\
\text { damage data }\end{array}$ \\
\hline & & $\begin{array}{l}\text { Quagwall } \\
\text { Gravity type }\end{array}$ & $275(77)$ \\
& & Steel sheet & $161(56)$ \\
& & pile type & \\
& \multirow{4}{*}{100} & Cellular type & $11(7)$ \\
& & Piled pire type & $31(17)$ \\
& & Breakwater & $40(11)$ \\
& & Other types & $161(39)$ \\
& & Total & $679(207)$ \\
\hline
\end{tabular}

Figures within parentheses are no damage data and are included in total of each type.

Fig. 2 Seismic Damage Deformation. 
and wall head) were used as the parameters to quantify the damage deformation.

b) Cost of seismic damage to gravity quaywalls

The cost of seismic damage to gravity quaywalls (seismic cost) means the outly assessed officially as repair work by the ministry of transport. In this report, the seismic cost was defined as the sum of the repair work cost divided by the damage length of gravity quaywall (unit : $1000 \mathrm{yen} / \mathrm{m}$ ). In this study, the ratio of the seismic cost to the initial construction cost was also discussed. This ratio is termed the cost rate of seismic damage (seismic cost rate).

The costs shown in the earthquake damage reports are the sums of the day. It was therefore required to convert these costs to same price level. Then, the fluctuation of the past years was investigated in the construction prices, in the wholesale prices of construction materials and in the wages respectively, and the fluctuation was quantified by a price index that is 100 for the prices at the year 1980 . The repair cost and the initial construction cost were converted to same price level by this price index ${ }^{2)}$.

\section{QUANTITATIVE ESTIMATION OF SEISMIC DAMAGE TO GRAVITY QUAYWALL BY ANALYSIS OF PAST DAMAGE DATA}

\section{(1) Assessment of damage occurrence}

A working seismic coefficient means the seismic coefficient which works on structures during earthquakes, and the relation between the working seismic coefficient and the maximum ground acceleration was presented as follows ${ }^{3)}$.

$$
\begin{aligned}
& K_{e}=\frac{\alpha}{g} \\
& K_{e}=\frac{1}{3}\left(\frac{\alpha}{g}\right)^{1 / 3} \quad(\alpha \geqq 200 \mathrm{Gal})
\end{aligned}
$$

where $K_{e}$ : Working seismic coefficient

$\alpha$ : Maximum ground acceleration (Gal)

$g$ : Acceleration of gravity $(980 \mathrm{Gal})$

For gravity quaywalls, the stability analysis should aim to derive the sliding and overturning behaviors as well as the bearing strength of the foundation, and also determine the seismic coefficient causing each of these failures under the safety factor of 1 . This seismic coefficient is termed the critical seismic coefficient. Critical seismic coefficients are given respectively in three stability examinations mentioned above. When the smallest of these critical seismic coefficients is smaller than the working seismic coefficient, the structure starts in break during earthquakes. This smallest critical seismic coefficient is defined as the breaking seismic coefficient.

A decision on whether or not damage would occur is based on the comparison between the working seismic coefficient and the breaking seismic coefficient. If the breaking seismic coefficient is greater than the working seismic coefficient, the structure is considered safe and earthquake resistant. Otherwise, the structure is expected to sustain damage due to the earthquake.

(2) Quantitative estimation of damage to gravity quaywall

As mentioned in the last paragraph the structure starts in break when the working seismic coefficient $\left(K_{e}\right)$ is greater than the breaking seismic coefficient $\left(K_{c}\right)$, and the quantitative damage that occurs to a structure is considered proportional to the ratio between $K_{e}$ and $K_{c}$. Therefore, a method to estimate the damage extent was presented in this study using this ratio between $K_{e}$ and $K_{c}$. The ratio of $K_{e}$ to $K_{c}$ was defined as the risk ratio $\left(F_{c}\right)$. The relationship between the seismic damage deformation and the risk ratio was then investigated on the basis of the regression analysis of the historical seismic damage data. In this analysis, the maximum swelling, the settlement of the face line, the damage deformation ratio and the seismic cost rate were discussed in this report.

Fig. 3 shows the relationship between seismic damage deformation ratio $\left(R_{g}\right)$ and the risk ratio $\left(F_{c}\right)$. This 
figure shows the extent of damage distinguished by the symbols. This extent of damage was classified into five categories between no damage and complete collapse ${ }^{2)}$. Table 2 shows the equations representing regressions. The regression formula of $R_{g}$ and $F_{c}$ in Fig. 3 was then given as follows.

$$
R_{g}=-12.7+14.5 F_{c}
$$

As shown in Table 2, correlation coefficients of the regression formula obtained here are not thoroughly high. In order to obtain a high accuracy, it is necessary to reexamine the relationship between the working seismic coefficient and the ground acceleration with higher accuracy, to investigate the relationship between the seismic damage deformation and the risk ratio for each failure mode, considering other factors of the ground condition and so on. However, no one knows whether a large number of damage data for regressions with a higher accuracy will be obtained or not in the near future. Therefore, it may be proper in the present situation to use the regression formula obtained here for this study.

The regression formula that represents the relationship between the seismic cost rate $\left(C_{f}\right)$ of the gravity quaywalls and the risk ratio $\left(F_{c}\right)$ was not obtained with high accuracy because of insufficient number of data covering the cost of seismic damage and the result of stability analysis to give the breaking seismic coefficient. Then, the relation between $C_{f}$ and $F_{c}$ was presented from the two regression formulae that are the equation of $C_{f}$ and the damage deformation ratio $\left(R_{g}\right)$ in Fig. 4, and that of $R_{g}$ and $F_{c}$ in Fig. 3 . According to these two formulae, the relationship between $C_{f}$ and $F_{c}$ can be given as follows.

$$
C_{f}=-62.2+66.2 F_{c}
$$

It was believed that this formula was obtained by means of the best method in the present situation in order to estimate the cost of gravity quaywalls for an optimum seismic coefficient from the economical viewpoint discussed in next chapter.

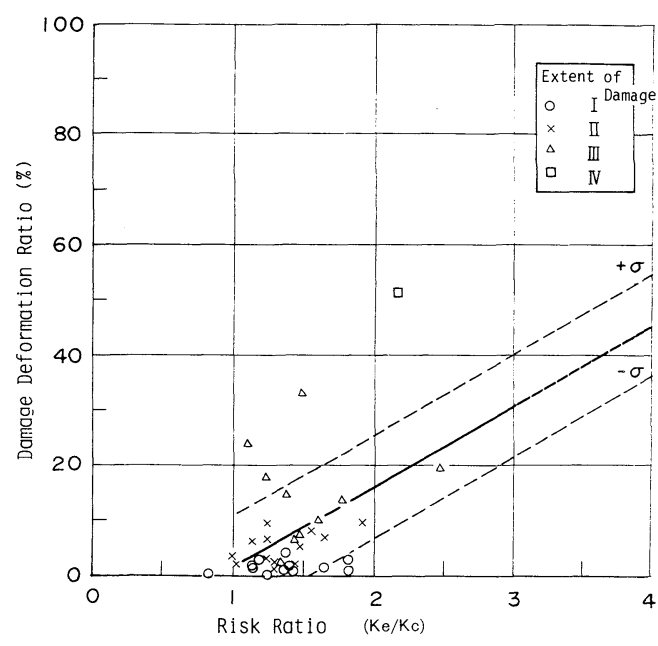

Fig. 3 Damage Deformation Ratio versus Risk Ratio.

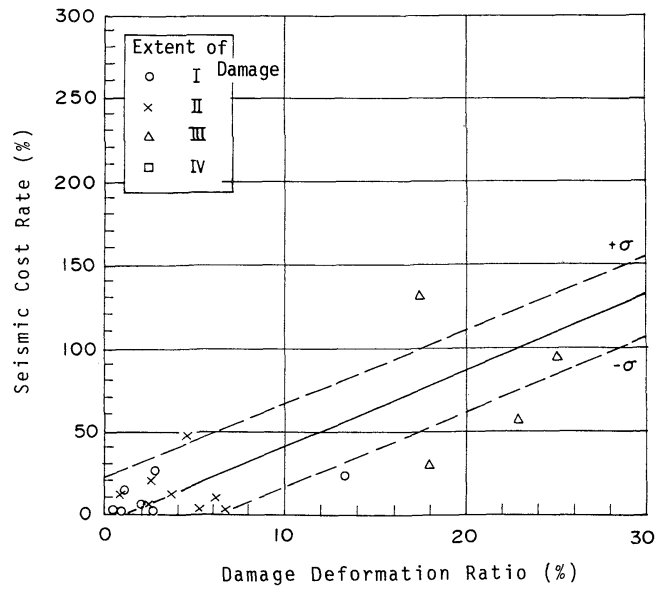

Fig. 4 Seismic Cost Rate versus Damage Deformation Ratio.

\begin{tabular}{|c|c|c|c|}
\hline Criterion variables & Regression formura & $\begin{array}{l}\text { Correlation } \\
\text { coefficient }\end{array}$ & $\begin{array}{l}\text { Standard } \\
\text { deviation }\end{array}$ \\
\hline $\begin{array}{c}\text { Maximum swelling } \\
(\mathrm{Dx}, \mathrm{Cm}) \\
\text { Settlement of face line } \\
(\mathrm{Sp}, \mathrm{Cm}) \\
\text { Damage def ormation ratio } \\
(\mathrm{Rg}, \boldsymbol{\%})\end{array}$ & $\begin{array}{l}D x=-113.8+124.4 F C \\
S p=-50 \cdot 9+57.1 F C \\
R g=-12 \cdot 7+14.5 F C\end{array}$ & $\begin{array}{l}0.559 \\
0.677 \\
0.455\end{array}$ & $\begin{array}{l}59.1 \\
20.0 \\
9.1\end{array}$ \\
\hline
\end{tabular}

Table 2 Results of Regression Analysis.

Predictor veriable $\left(F_{\mathrm{c}}\right)$ : Risk Ratio $\left(K_{e} / K_{\mathrm{c}}\right)$ 


\section{OPTIMUM SEISMIC COEFFICIENT AND ALLOWABLE RESIDUAL DISPLACE- MENT FROM ECONOMICAL VIEWPOINT}

\section{(1) Concept of optimum seismic coefficient ${ }^{4), 5)}$ and allowable residual displacement}

One of the seismic coefficient given by the rational earthquake resistant design method is the optimum seismic coefficient from the economical viewpoint. The factors to affect the definition of an optimum seismic coefficient from an economical viewpoint are the initial construction cost, the cost of seismic damage to the structures, the utility of repair works to local economics, the effect of port constructions on the environment and so on. At the present time, it is very difficult to quantify these factors other than the initial construction cost and the cost of seismic damage to structures. Therefore the economical viewpoint in this report focused on these two factors for the first step to define the optimum seismic coefficient.

When the seismic coefficient becomes larger, the expected cost of seismic damage to structures (expected seismic cost : $\left.C_{f}(k)\right)$ decreases, and the initial construction cost $\left(I_{c}(k)\right)$ increases, as shown in Fig. 5. Therefore, it is believed that the sum of the initial construction cost and the expected seismic cost (expected total cost : $C_{t}(k)$ ) shows a raised down curves with the extreme. In this report, the seismic coefficient which gives the extreme of this $C_{t}(k)$ is defined as optimum seismic coefficient from an economical viewpoint. And the seismic coefficient in this study is assumed to be the same as the breaking seismic coefficient because the seismic coefficient of the present design method for the gravity quaywall is nearly equal to the breaking seismic coefficient.

An allowable residual displacement for the earthquake resistant design from the economical viewpoint was investigated in this paper as described in Chapter 1 . The allowable residual displacement was defined as the expected seismic damage displacement given by the optimum seismic coefficient mentioned in the last paragraph.

The accuracy of estimating the expected seismic costs discussed here is not necessarily very high, considering the scattering of the expected seismic costs and that of the acceleration for the attenuation curves with distance. However, the study on the quantitative estimation of the expected seismic cost is the first stage in earthquake engineering. It was still considered for this study to be currently useful.

\section{(2) Relation between initial construction cost and seismic coefficient}

The initial construction cost of a given gravity revetment which was designed for the two kinds of foundation ground of a sand layer and a clay layer, and for several seismic coefficients was estimated ${ }^{2}$. Fig. 6 shows this initial construction cost versus seismic coefficient. The vertical axis in Fig. 6 is the ratio of the initial construction cost for each seismic coefficient to that for the ordinary condition.

The relationship between the initial construction cost and the seismic coefficient for port facilities had been reported in the study on the economical design of port facilities by Murata, Yagyu and Uchida ${ }^{6}$. Fig. 7 shows the initial construction cost against the seismic coefficient for the gravity quaywall where structure is of the caisson type shown in Fig. 8. It is necessary to pay attention to the price level of the year 1976 and the unit of vertical axis that is $10000 \mathrm{yen} / \mathrm{m}$.

\section{(3) Expected seismic cost rate}

a) Cumulative distribution function and probability density function of maximum ground acceleration at Japanese ports

The probability of the occurrence of the maximum ground acceleration at a given site was studied here based on the report of Kitazawa, Uwabe and Higaki ${ }^{7}$. Fig. 9 shows the base rock acceleration against the return

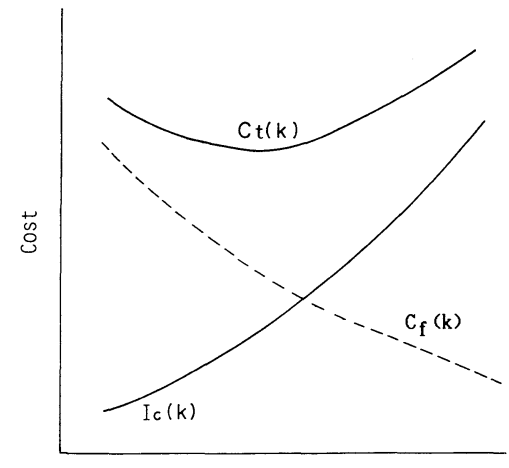

Seismic Coefficient

Fig. 5 Relation between Cost and Seismic Coefficient 


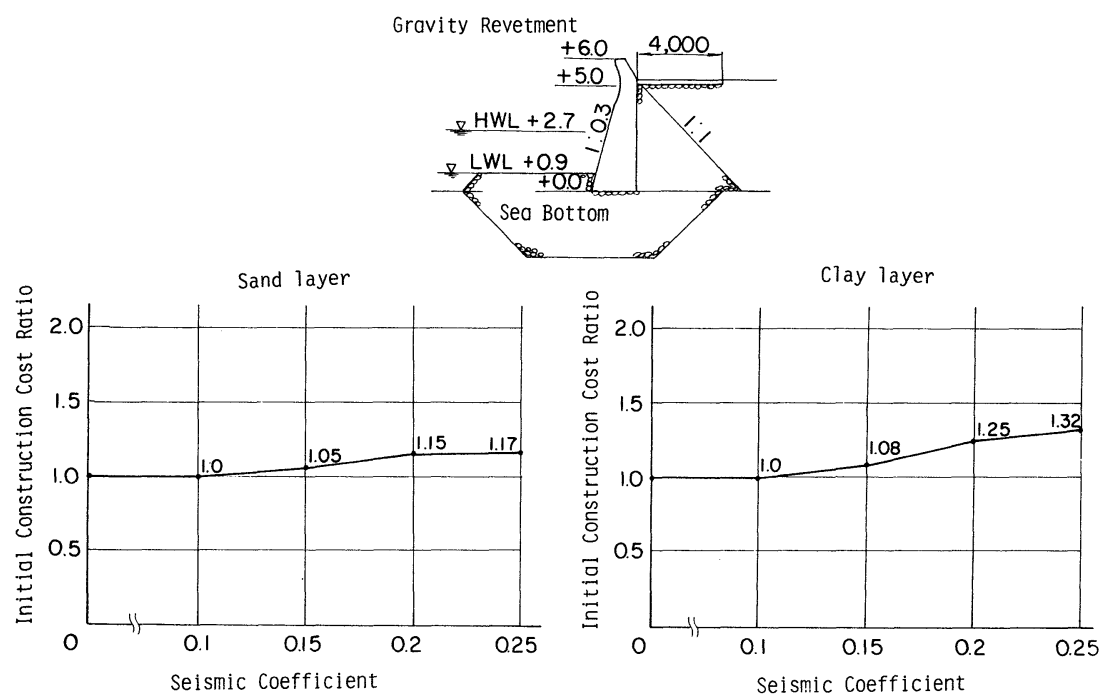

Fig. 6 Initial Construction Cost versus Seismic Coefficient (Gravity Revetment).

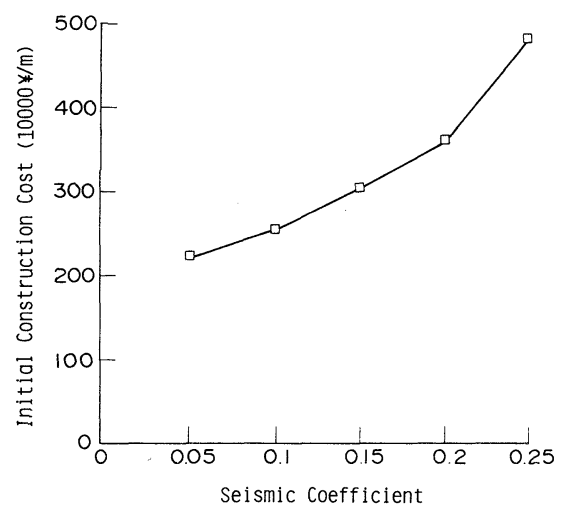

Fig. 7 Initial Construction Cost versus Seismic Coefficient (Murata et al. ${ }^{6)}$ ).

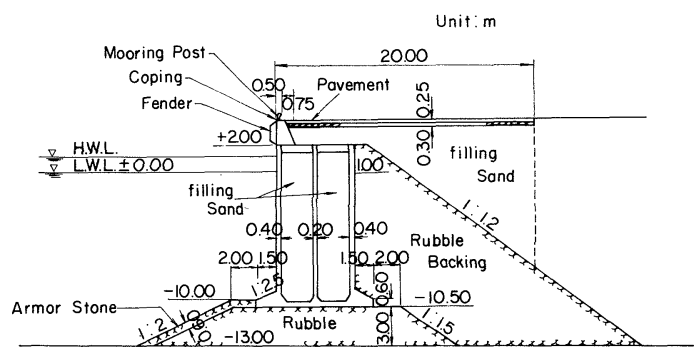

Fig. 8 Standard Section of Caisson Type Quaywall (Murata et al. ${ }^{6)}$ ).
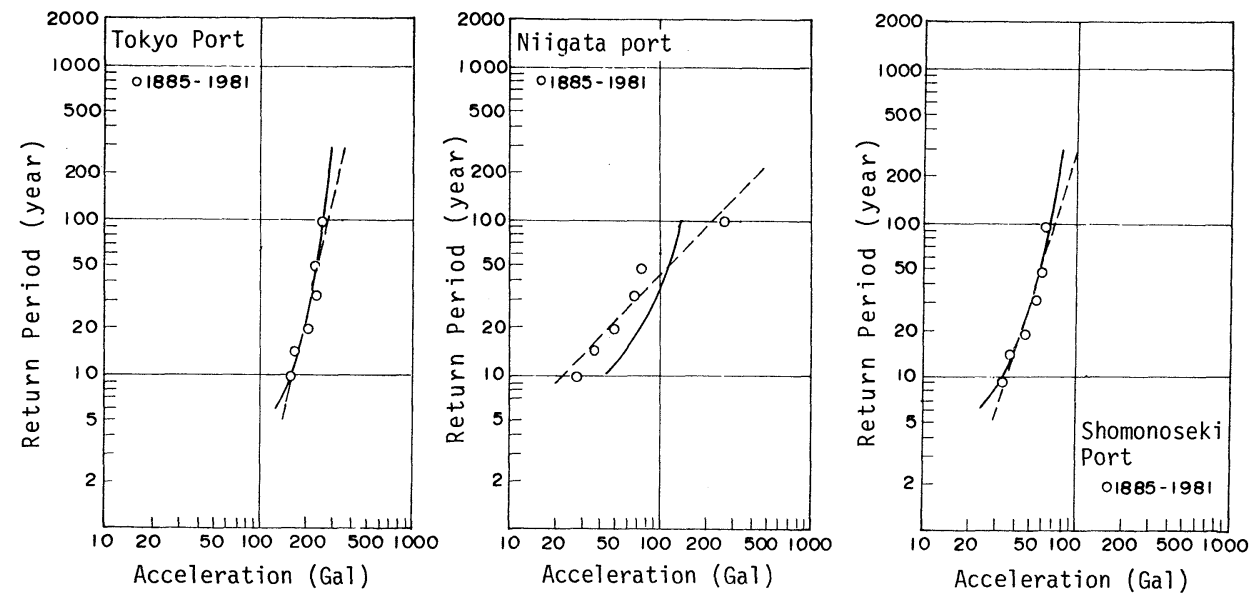

Fig. 9 Maximum Base Rock Acceleration versus Return Period. 
period at Tokyo, Niigata and Shimonoseki. These three ports were selected from the viewpoint of probability of earthquake occurrence. According to Fig. 9, the maximum base rock accelerations for the return period of 50 years are about $240 \mathrm{Gal}$ at Tokyo port, about $120 \mathrm{Gal}$ at Niigata port and about $60 \mathrm{Gal}$ at Shimonoseki port.

The cumulative distribution function and probability density function of $t$ durable year were obtained as follows ${ }^{8,9)}$.

$$
\begin{aligned}
& F_{m}\left(X_{m}\right)=\left\{\left(1-\frac{N}{K}\right)+\frac{N}{K} \cdot \exp \left(-m \cdot e^{\left.-\frac{X_{m}-B}{A}\right)} \cdot\left(\sum_{n=1}^{m} \frac{m^{(n-1)}}{(n-1) !} \cdot e^{-(n-1) \frac{X_{m}-B}{A}}\right)\right\}^{t} \cdots\right. \\
& f_{m}\left(X_{m}\right)=\frac{m^{m}}{(m-1) !} \cdot \frac{t \cdot N}{A \cdot K}\left\{\left(1-\frac{N}{K}\right)+\frac{N}{K} \cdot \exp \left(-m \cdot e^{-\frac{X_{m}-B}{A}}\right) \cdot\left(\sum_{n=1}^{m} \frac{m^{(n-1)}}{(n-1) !} \cdot e^{-(n-1) \frac{X_{m}-B}{A}}\right)\right\}^{t-1} \\
& \cdot \exp \left(-m \cdot \frac{X_{m}-B}{A}-m \cdot e^{-\frac{X_{m}-B}{A}}\right)
\end{aligned}
$$

where $X_{m}: M$-th acceleration

$A, B$ : Constant of Gumbel distribution

$N$ : Number of data

$K:$ Period of earthquake data

$t$ : Durable years

$m$ : Order of extreme

Fig. 10 shows the distribution function and the probability density function for Tokyo port. The probability density function of the maximum anticipated acceleration at Tokyo port for the durable year of 50 years is $f_{1}(x)$ in Fig. 10, and the acceleration of about 240 Gal where $f_{1}(x)$ shows a peak is the same as the expected acceleration for the return period of 50 years in Fig. 9.

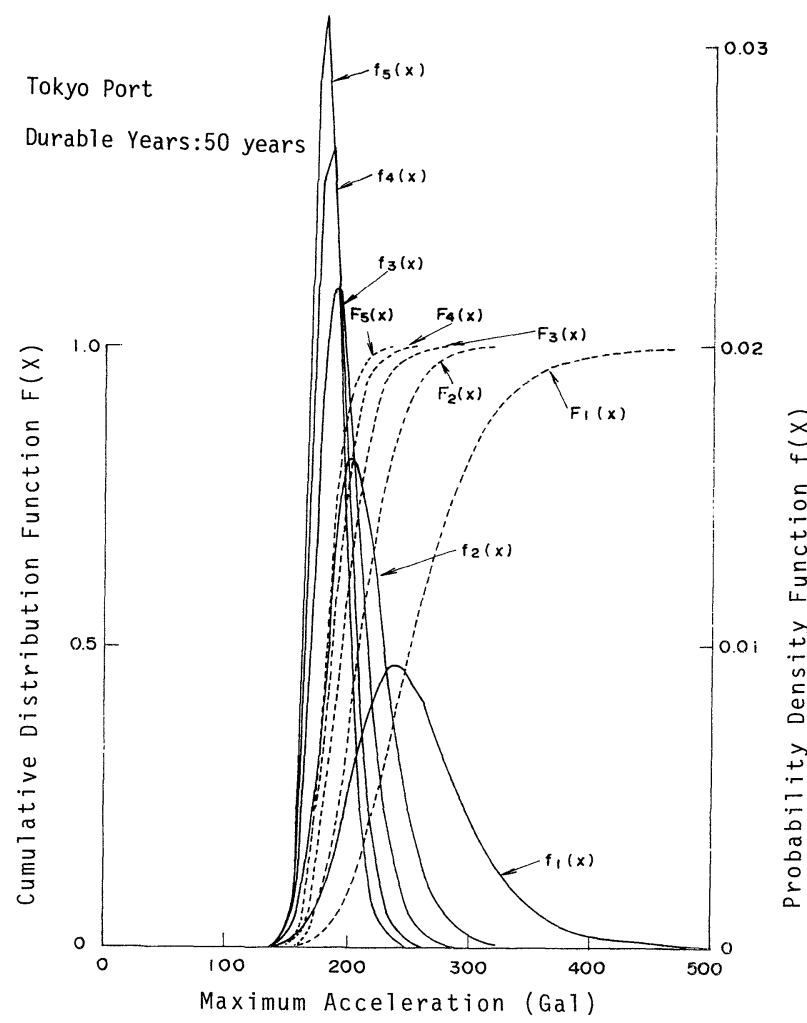

Fig. 10 Distribution Function and Probability Density Function (Tokyo Port). b) Expected seismic cost rate

When the distribution function of the $m$-th extreme is $f_{m}(x)$, the probability of occurrence of the $m$-th extreme is $f_{m}(x) d x$. The expected seismic cost rate is derived from $f_{m}(x) d x$ and random variable $D(x)$ which is the seismic cost rate as follows.

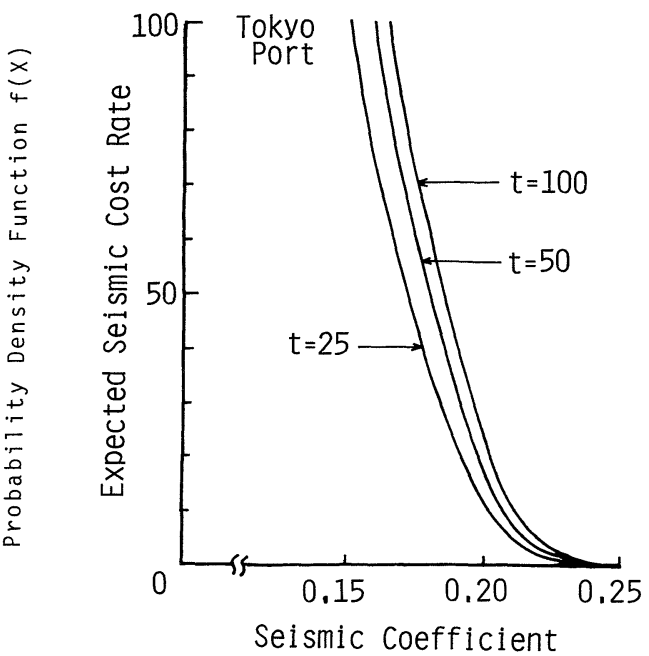

Fig. 11 Expected Seismic Cost Rate versus Seismic Coefficient. 


$$
P_{c f}=\sum^{m} \int_{(x)} D(x) f_{m}(x) d x
$$

Moreover, $D(x)$ is given by the equation of (3). In case of expected seismic damage deformation ratio, $D(x)$ is given by the equation of (2). As the extreme of large order had little influence on the expected seismic cost rate, the extremes from 1 st to 5 th were considered for the calculation of the expected seismic cost rate. Fig. 11 shows the expected seismic cost rate of Tokyo port for durable years of 25, 50 and 100 .

\section{(4) Optimum seismic coefficient and allowable residual displacement}

Optimum seismic coefficients to minimize the expected total cost were calculated for Tokyo port, Niigata port and Shimonoseki port. The number of durable years was 50, and the extremes from 1 st to 5 th were considered. The relations between the initial construction cost and the seismic coefficient in Fig. 6 and 7 were used. As the amount of the initial construction cost in Fig. 6 was not shown, it was supposed that the initial construction cost of the ordinary condition was $1000000 \mathrm{yen} / \mathrm{m}$. As the year of the price level in Fig. 7 is the year 1976, the amount of expected seismic cost was converted in the price level of the year 1980.

Results of the calculation are shown in Fig. 12 for the gravity revetment and in Fig. 13 for the gravity quaywall (Caisson type). The solid lines with symbols of $X$ in Fig. 12 and 13 show the initial construction cost. The solid lines with closed circles, open circles and squares show the expected seismic cost. The dotted lines show the expected total cost. Table 3 shows the optimum seismic coefficient to minimize the expected total cost in Fig. 12 and 13.

The optimum seismic coefficients obtained here, were compared with the expected maximum ground acceleration with a return period of 50 years. Table 3 shows the seismic coefficients transformed from the expected maximum ground accelerations for a return period of 50 years in Fig. 9, using Eq. (1). In the case of gravity revetments, the optimum seismic coefficients were larger than the seismic coefficients for a return period of 50 years. In the case of gravity quaywalls, the optimum seismic coefficients were the same as the seismic coefficients at Tokyo port and were slightly larger than those at Niigata port and Shimonoseki port.

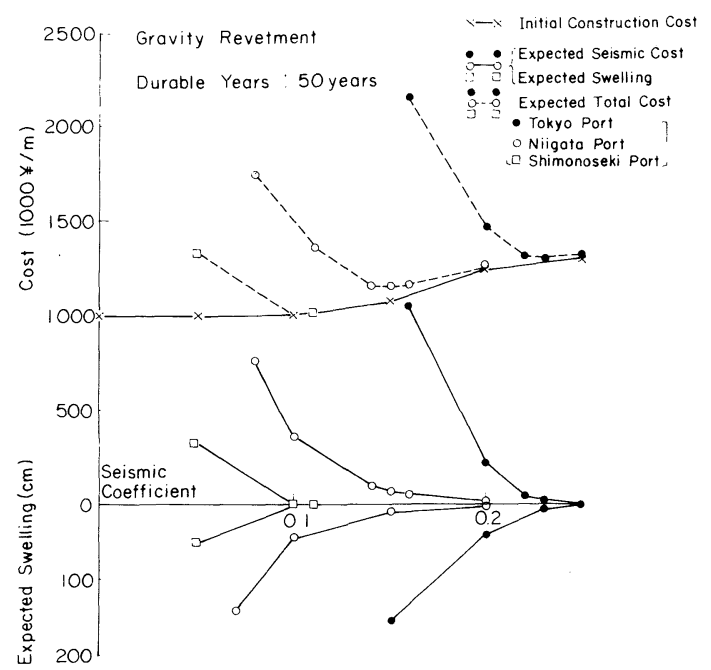

Fig. 12 Expected Total Cost versus Seismic Coefficient (Gravity Revetment).

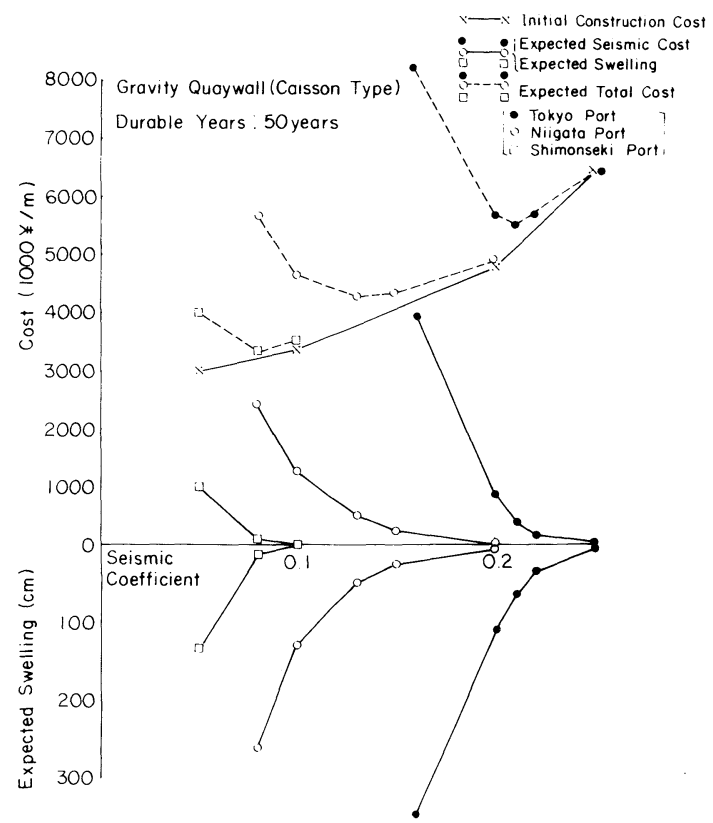

Fig. 13 Expected Total Cost versus Seismic Coefficient (Gravity Quaywall). 
Table 3 Optimum Seismic Coefficient and Allowable Residual Displacement.

\begin{tabular}{|c|c|c|c|c|c|}
\hline \multirow{2}{*}{$\begin{array}{c}\text { Nane of } \\
\text { port }\end{array}$} & \multicolumn{2}{|c|}{ Optimu seismic coef. } & \multirow{2}{*}{$\begin{array}{l}\text { Seisuic coef. } \\
\text { (Return period } \\
\text { of } 50 \text { years) }\end{array}$} & \multicolumn{2}{|c|}{ Allowable residual dis. (c) } \\
\hline & Revetment & Quaywall & & Revetment & Quaywall \\
\hline $\begin{array}{c}\text { Tokyo } \\
\text { Niigata } \\
\text { Shimonoseki }\end{array}$ & $\begin{array}{l}0.23 \\
0.15 \\
0.10\end{array}$ & $\begin{array}{l}0.21 \\
0.13 \\
0.08\end{array}$ & $\begin{array}{l}0.21 \\
0.12 \\
0.06\end{array}$ & $\begin{array}{r}5 \\
10 \\
1\end{array}$ & $\begin{array}{l}67 \\
50 \\
10\end{array}$ \\
\hline
\end{tabular}

Fig. 12 and 13 show the expected maximum swelling calculated from Eq. (2). The height of structures is $5 \mathrm{~m}$ for the gravity revetment and is $14 \mathrm{~m}$ for the gravity quaywall. The expected maximum swellings of the optimum seismic coefficient are as follows. In the case of the gravity revetment, the expected values of maximum swelling were $5 \mathrm{~cm}$ at Tokyo port, $10 \mathrm{~cm}$ at Niigata port and $1 \mathrm{~cm}$ at Shimonoseki port. The reason why the expected maximum swelling at Tokyo port is smaller than that at Niigata is that the increasing rate of the initial construction cost between 0.15 and 0.2 is larger than that between 0.2 and 0.25 . In the case of the gravity quaywall, the expected values of the maximum swelling were $67 \mathrm{~cm}$ at Tokyo port, $50 \mathrm{~cm}$ at Niigata port and $10 \mathrm{~cm}$ at Shimonoseki port. This displacement is an allowable residual displacement, when defined from an economical viewpoint. In addition to displacement discussed here, an allowable displacement from the viewpoint of the berthing function, the structural stability and so on should be examined for the rational earthquake resistant design.

\section{CONCLUSION}

Data on cases of seismic damage to gravity quaywalls were collected. Then the quantification of the earthquake damage and the quantitative estimation method of seismic damage to gravity quaywalls were investigated. The relation between the damaged deformation ratio and the risk ratio which is the ratio of the working seismic coefficient to the breaking seismic coefficient, and the relation between the seismic cost ratio and the risk ratio were obtained on the seismic damage data of gravity quaywalls in past earthquakes.

Moreover, the procedure to give an optimum seismic coefficient from an economical viewpoint and the allowable residual displacement which was defined as the expected seismic damage displacement given by such optimum seismic coefficient was presented, using the method for estimating the cost of seismic damage to gravity quaywalls. The optimum seismic coefficients and the allowable residual displacement of the gravity revetments and quaywalls were obtained from the expected total cost with the durable period of 50 years at Tokyo port, Niigata port and Shimonoseki port. The result of a comparison between these otimum seismic coefficients and the working seismic coefficient calculated from the expected maximum ground acceleration for the return period of 50 years were as follows. In the case of gravity revetments the optimum seismic coefficient was larger than the working seismic coeffcient with the return period of 50 years. In the case of gravity quaywalls the optimum seismic coefficients were same as the working seismic coefficient at Tokyo port and were slightly larger than those at Niigata port and Shimonoseki port. Th working seismic coefficients in Table 3 are nearly equal to the seismic coefficient used in the present design method of gravity quaywalls for each port. As the seismic coeffcient of the present design method had been established empirically on the base of the past earthquake damage, it seems that the result of this study on the optimum seismic coefficient shows the validity of the empirical engineering judgment from the economical viewpoint for the seismic coefficient.

\section{REFERENCES}

1) Tsuchida, H., Noda, S., Inatomi, T., Uwabe, T., Yagyu, T., and Murata, T. : Method of Evaluation for Seismic Stability of Port and Coastal Facilities, Technical Note of the Port and Harbour Research Institute (PHRI), No. 336, June 1980.

2) Uwabe, T. : Estimation of Earthquake Damage Deformation and Cost of Quaywalls based on Earthquake Damage Records, Technical Note of PHRI, No.473, Dec. 1983. 
3) Noda, S., Uwabe, T. and Chiba, T. : Relation between Seismic Coefficient and Ground Acceleration for Gravity Quaywall, Report of PHRI, Vol.14, No.4, pp.67-111, Dec. 1975.

4) Nonaka, M., Inokuma, Y. and Katayama, T. : Studies on Seismic Damage Rate and Optimum Seismic Coefficient Determination of Highway Bridges, Proc. of JSCE, No.340, pp. 87-96, Dec. 1983.

5) Matsuo, M. : Reliability in Geotechnical Engineering Design, Gihodo Press, March 1984.

6) Murata, T., Yagyu, T. and Uchida, T. : Some Consideration on Profitable Designing for Port and Harbour Facilities, Proc. of 1980 Annual Research Presentation of PHRI, pp.233-276, Dec. 1980.

7) Kitazawa, S., Uwabe, T. and Higaki, N. : Expected Values of Maximum Base Rock Acceleration along Coasts of Japan, Technical Note of PHRI, No. 486, July 1984.

8) Gumbel, E. J. : Statistics of Extremes (Japanese translation version), Seisan-Gijyutsu-Senta-Shinsya, June 1978.

9) Uwabe, T. : Study on Quantitative Estimation of Seismic Damage to Gravity Quaywall, Technical Note of PHRI, No. 548, June 1986.

(Received July 18 1988) 